\title{
Durability and Survivability of Piezoelectric Wafer Active Sensors on Metallic Structure
}

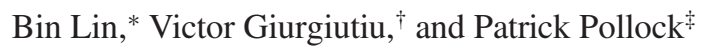 \\ University of South Carolina, Columbia, South Carolina 29208 \\ Buli Xuํㅗ \\ Georgia Institute of Technology, Atlanta, Georgia 30332 \\ and \\ James DoaneI \\ Indiana Tech, Fort Wayne, Indiana 46803
}

\begin{abstract}
DOI: $\underline{10.2514 / 1.44776}$
Piezoelectric wafer active sensors are small, inexpensive, noninvasive, elastic wave generators/receptors that can be easily affixed to a structure. Piezoelectric wafer active sensor installation on the health-monitored structure is an important step that may have significant bearing on the success of the health monitoring process. The purpose of this paper is to explore the durability and survivability issues associated with various environmental conditions on piezoelectric wafer active sensors for structural health monitoring. The durability and survivability of the piezoelectric wafer active sensor transducers under various exposures (cryogenic and high temperature, temperature cycling, outdoor environment, operational fluids, large strains, fatigue load cycling) were considered over a long period of time. Both free piezoelectric wafer active sensors and bonded piezoelectric wafer active sensors on metallic structural substrates were used. Different adhesives and protective coatings were compared to find the candidate for piezoelectric wafer active sensor application in structural health monitoring. In most cases, piezoelectric wafer active sensors survived the tests successfully. The cases when piezoelectric wafer active sensors did not survive the tests were closely examined and possible causes of failure were discussed. The test results indicate that lead zirconate titanate piezoelectric wafer active sensors can be successfully used in a cryogenic environment; however, it does not seem to be a good candidate for high temperature. Repeated differential thermal expansion and extended environmental attacks can lead to piezoelectric wafer active sensor failure. This emphasizes the importance of achieving the proper design of the adhesive bond between the piezoelectric wafer active sensor and the structure, and of using a protective coating to minimize the ingression of adverse agents. The high-strain tests indicated that the piezoelectric wafer active sensors remained operational up to at least 3000 microstrain and failed beyond 6000 microstrain. In the fatigue cyclic loading, conducted up to 12 millions of cycles, the piezoelectric wafer active sensor transducers sustained at least as many fatigue cycles as the structural coupon specimens on which they were installed.
\end{abstract}

\section{Introduction}

$\mathbf{E}$ MBEDDED nondestructive evaluation (NDE) is an emerging technology that will allow the transition of the conventional ultrasonics methods to embedded structural health monitoring (SHM) systems such as those envisioned for vehicle health management. SHM requires the development of small, lightweight, inexpensive, unobtrusive, minimally invasive sensors to be embedded in the airframe with minimum weight penalty and at affordable costs. Such sensors should be able to scan the structure and identify the presence of defects and incipient damage. Current ultrasonic inspection of thin-wall structures (e.g., aircraft shells, storage tanks, large pipes, etc.) is a time-consuming operation that requires meticulous throughthe-thickness C-scans over large areas. One method to increase the efficiency of thin-wall structure inspection is to use guided waves

Received 6 April 2009; revision received 24 August 2009; accepted for publication 3 October 2009. Copyright $\odot 2009$ by Bin Lin; Victor Giurgiutiu; Patrick Pollock; Buli Xu; James Doane. Published by the American Institute of Aeronautics and Astronautics, Inc., with permission. Copies of this paper may be made for personal or internal use, on condition that the copier pay the $\$ 10.00$ per-copy fee to the Copyright Clearance Center, Inc., 222 Rosewood Drive, Danvers, MA 01923; include the code 0001-1452/10 and $\$ 10.00$ in correspondence with the CCC.

${ }^{*}$ Graduate Student, Department of Mechanical Engineering, 300 Main Street; linbin@cec.sc.edu.

${ }^{\dagger}$ Professor, Department of Mechanical Engineering, 300 Main Street; victorg@sc.edu.

${ }^{\ddagger}$ Graduate Student, Department of Mechanical Engineering, 300 Main Street.

${ }^{\S}$ Postdoctoral Research Scientist, School of Aerospace Engineering.

${ }^{\top}$ Assistant Professor, Mechanical Engineering. (e.g., Lamb waves) instead of the conventional pressure waves. Guided waves propagate along the midsurface of thin-wall plates and shallow shells. They can travel at relatively large distances with very little amplitude loss and offer the advantage of large-area coverage with a minimum of installed sensors. Guided Lamb waves have opened new opportunities for cost-effective detection of damage in aircraft structures, and a large number of papers have recently been published on this subject. Traditionally, guided waves have been generated by impinging the plate obliquely with a tone-burst from a relatively large ultrasonic transducer. Snell's law ensures mode conversion at the interface, hence a combination of pressure and shear waves are simultaneously generated into the thin plate. However, conventional Lamb-wave probes (wedge and comb transducers) are relatively too heavy and expensive to consider for widespread deployment on an aircraft structure as part of a SHM system. Hence, a different type of sensor than the conventional ultrasonic transducers is required for the SHM systems. Piezoelectric wafer active sensors (PWAS) are inexpensive, nonintrusive, unobtrusive devices that can be used in both active and passive modes. In active mode, PWAS generated Lamb waves that can be used for damage detection through pulse-echo or pitch-catch techniques. The electrical impedance of PWAS can be directly related to the mechanical impedance of a host structural component where the PWAS is attached.

\section{State of the Art}

Piezoelectric wafer active sensors can send and receive ultrasonic Lamb waves and determine the presence of cracks, delaminations, disbands, and corrosion. In recent years investigators (Chang $[\underline{1}, \underline{2}]$, 
Table 1 Properties of a typical piezoelectric wafer active sensor (APC-850)

\begin{tabular}{lcc}
\hline \hline Property & Symbol & Value \\
\hline Compliance & $S_{11}^{E}$ & $15.30 \cdot 10^{-12} \mathrm{~Pa}^{-1}$ \\
Dielectric constant & $\varepsilon_{33}^{T}$ & $15.47 \cdot 10^{9} \mathrm{~F} / \mathrm{m}$ \\
Induced strain coefficient & $d_{13}$ & $-175 \cdot 10^{-12} \mathrm{~m} / \mathrm{V}$ \\
Coupling factor & $\kappa_{31}$ & 0.360 \\
\hline \hline
\end{tabular}

Wang and Chang [3], Lin and Yuan [4,5], Ihn and Chang [6], Giurgiutiu [7], and others) have explored the generation and detection of structural waves with PWAS. These successful experiments have positioned PWAS as an enabling technology for the development and implementation of active SHM systems. Crawley and de Luis [8], Sirohi and Chopra [9], and Giurgiutiu [7] studied the shear lag effect caused by a bond layer. Park [10] reviewed the development and application of the impedance-based structural health monitoring technique. A modified EM impedance model by incorporating the effect of bond layers was proposed by $\mathrm{Xu}$ and Liu [11]. The durability and survivability of PWAS in different aspects were investigated by many researchers. Park et al. investigated the degradation or failure of PWAS and how its bond with structure may affect the impedance readings and the Lamb-wave propagations [12]. Isogai et al. [13] have done the study of piezoelectric actuator responsive to environmental humidity. Wang et al. [14] have studied the piezoelectric ceramics stress corrosion cracking in water, methanol, and formamide at a constant load test. Qing et al. [15,16] determine the survivability and functionality of a lead zirconate titanate (PZT) SMART tape at cryogenic temperature. Sakai et al. [17] have found out that the coercive field and mechanical strength of PZT can be improved by doping various additives to improve the durability of PZT ceramics. Another study of the effect of thermal cycling on the performance of PWAS bonded to aluminum plates has been done by Blackshire et al. [18]. It was observed that the amplitude of the excited elastic wave reduced after thermal cycling. However, durability and survivability of PWAS and its bond with structure has not been well established.

\section{Overview of Piezoelectric Wafer Active Sensor Durability and Survivability Studies}

PWAS used in this durability tests were circular PWAS with $7 \mathrm{~mm}$ diameter and $0.2 \mathrm{~mm}$ thick. The PWAS was made of PZT APC-850 material by APC International, Ltd. PZT APC-850 was chosen because of its material properties (Table 1), which are balanced for both actuating and sensing. The dimension and capacitance of free PWAS were measured before installation to test the consistency of sensors. Free PWAS dimensions and capacitances in this experimental setup were all within the bounds of statistical quality control for the tolerances that the manufacturer states.

A number of studies have been performed to assess PWAS durability and survivability of extreme temperature exposure, exposure

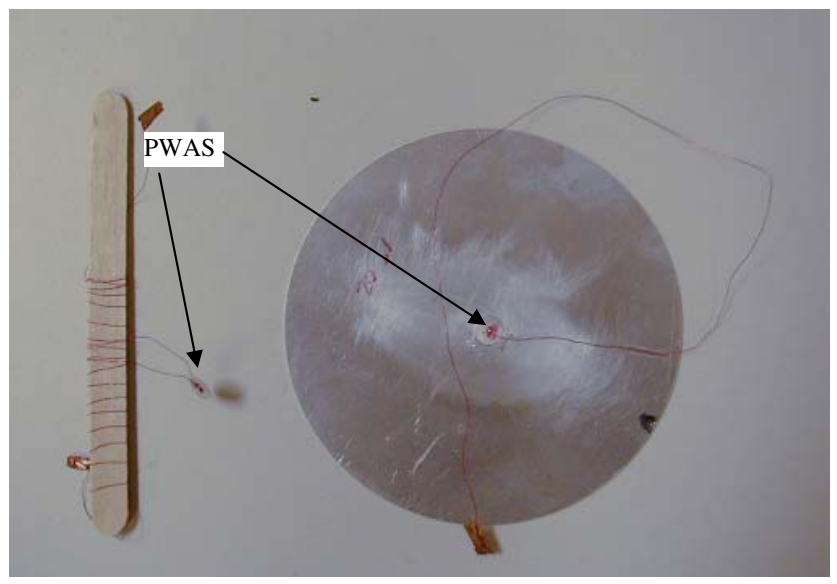

Fig. 1 Free PWAS and attached PWAS.
Table 2 Adhesives' operating temperature

\begin{tabular}{lrrc}
\hline \hline & M-Bond 200 & M-Bond 610 & AE-15 \\
\hline Short term & -300 to $+200^{\circ} \mathrm{F}$ & -452 to $+700^{\circ} \mathrm{F}$ & - \\
Long term & -25 to $+150^{\circ} \mathrm{F}$ & -452 to $+500^{\circ} \mathrm{F}$ & -452 to $+200^{\circ} \mathrm{F}$. \\
\hline \hline
\end{tabular}

to environmental factors (sun, rain, humidity, freeze-thaw, etc.), exposure to water and maintenance fluids, large strains, and fatigue cyclic loads. The durability and survivability studies of the PWAS under various exposures were considered to verify the durability of PWAS over a long period time. The durability and survivability of the PWAS transducers under various environmental exposures was tested in several stages as follows: 1) cryogenic temperature, 2) high temperature, 3) temperature cycling, 4) outdoor environment, 5) operational fluids, and 6) fatigue load cycling.

Both free PWAS and bonded PWAS were studied (Fig. 1). Free PWAS were tested with two wires attached on both electrodes. The bonded PWAS specimens were made by attaching PWAS onto the center of a $100 \mathrm{~m}$ diameter $1 \mathrm{~mm}$ thick aluminum plate. The PWAS behavior was monitored using the electromechanical (EM) impedance method. Giurgiutiu [7] and others established a complete analytical model of free and bonded PWAS on circular plates as function of material properties of PWAS and structures. The analytical model results have been verified by experimental results and finite element simulation. For a free PWAS, the real part of the EM impedance reflects its free vibration spectrum. For a bonded PWAS, the real part of the EM impedance directly reflects the vibration spectrum of the tested specimen through the pointwise mechanical impedance at the point where PWAS is attached to the structure.

In the installation process, the adhesive used to bond the PWAS to the structure plays a crucial role. The thickness and stiffness of the adhesive layer can significantly influence the sensor's capability to excite the structure and may affect the quality and repeatability of the EM impedance signatures. Cyanoacrylate adhesives are appropriate and convenient for short-term experiments, though their performance degrades under prolonged environmental exposure, which has been proved by the durability tests. For long-term environmental exposure, other adhesive types (e.g., epoxy) may be more appropriate. The use of conductive epoxy can ignore its contribution to sensor-structure interaction but it shorts the electrode unexpectedly. The adhesives used in this study were cyanoacrylate M-Bond 200, epoxy M-Bond 610, and epoxy AE-15 from Measurements Group, Inc. Because of the wide temperature range involved in this experiment, extra care must be taken for the bonding of sensors. The short and long term of the adhesives' operating temperatures are listed in Table 2 .

\section{A. Cryogenic Temperature}

At atmospheric pressure, liquid nitrogen boils at $-321 \mathrm{~F}$ $(-196 \mathrm{C})$ and is a cryogenic fluid. Free and bonded PWAS were

\section{Free PZT PWAS}

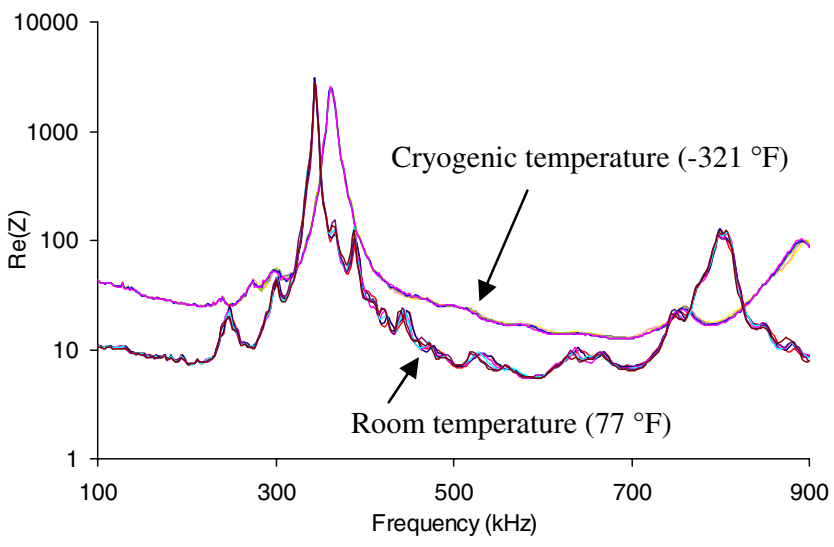

Fig. 2 Indication of free PWAS operability while submersed in liquid nitrogen. 


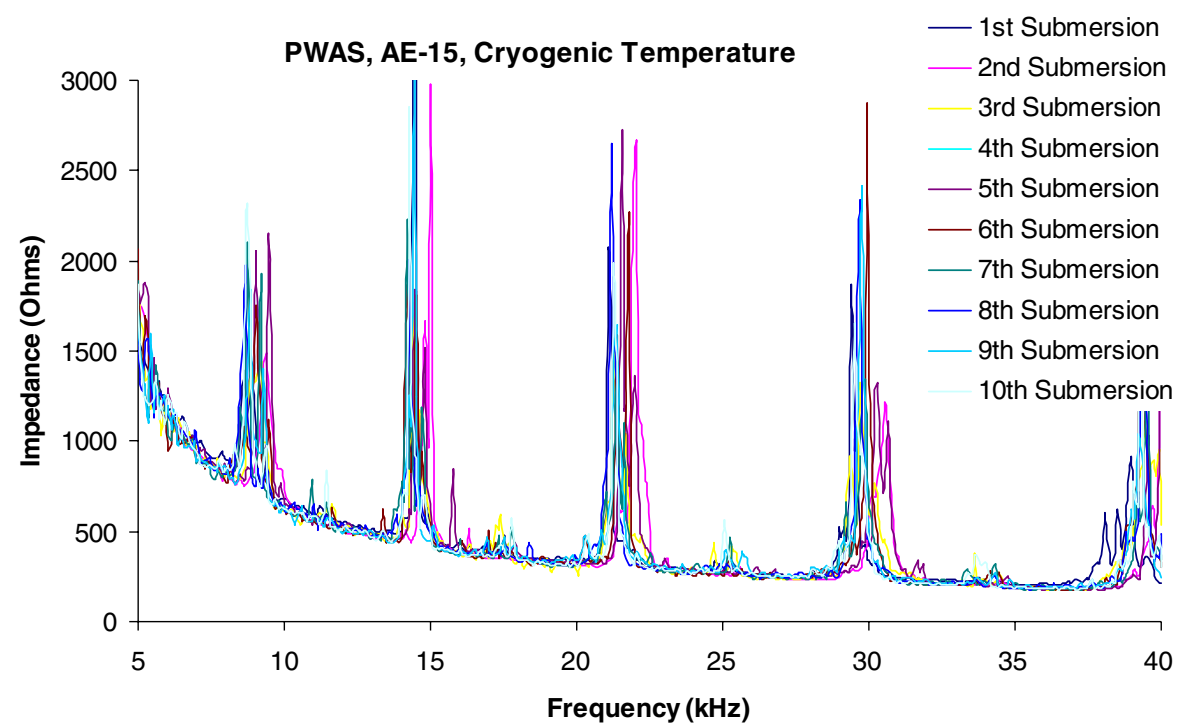

Fig. 3 The real part of impedance indication of operability through retention of resonant properties while submersed in liquid nitrogen.

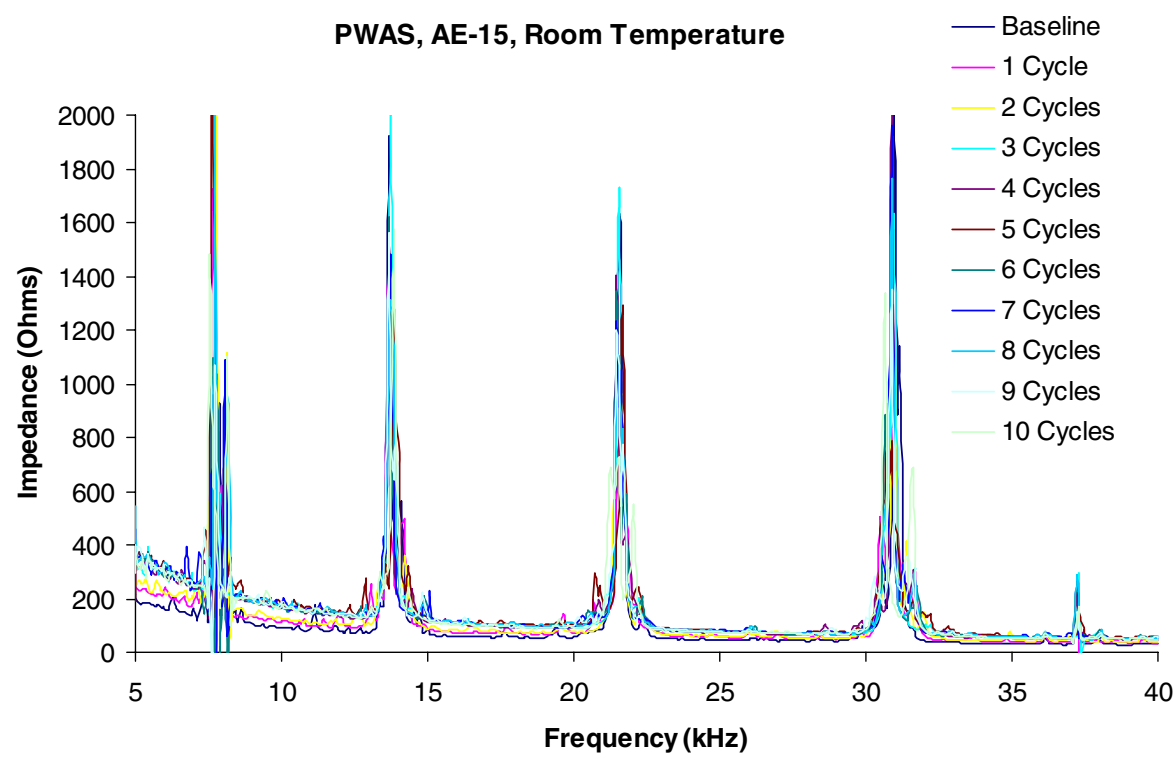

Fig. 4 The real part of impedance indication of survivability through resumption of resonant properties at room temperature after submersion in liquid nitrogen.

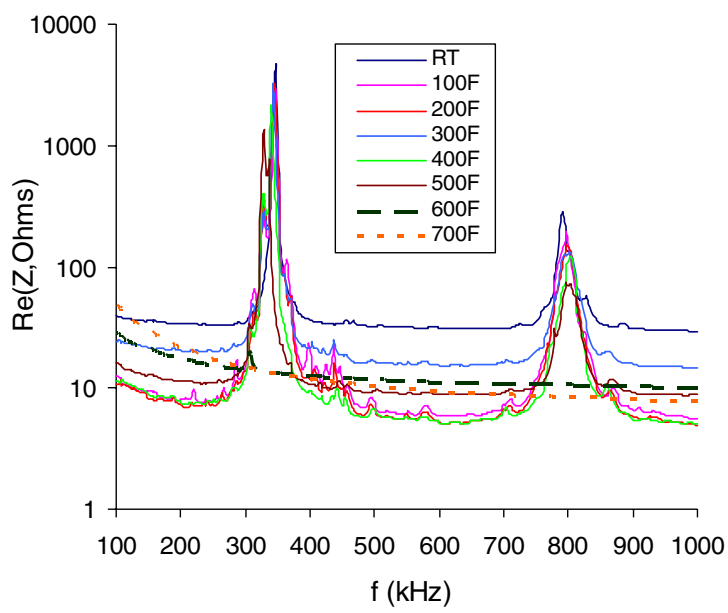

a)

Fig. 5 Real part impedance spectrum of a free PWAS: a) impedance at room temperature after heating, and b) amplitude of impedance peak at room temperature after heating. 


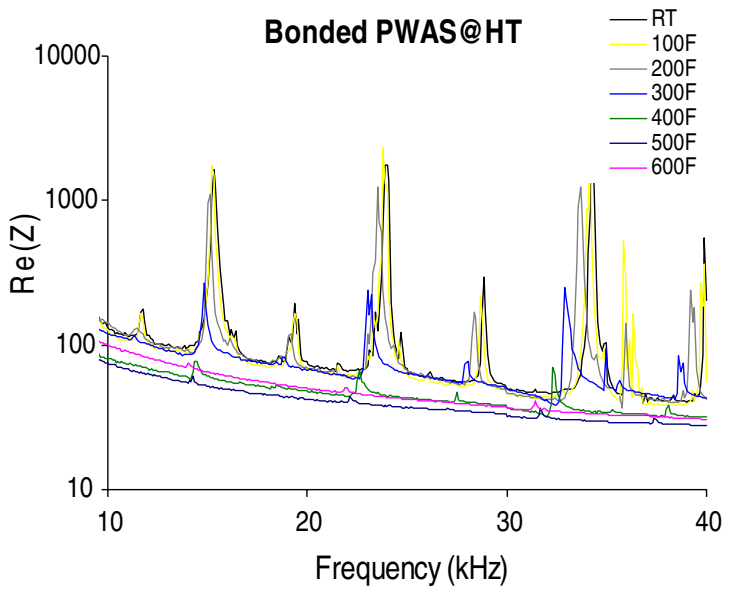

a)

Fig. 6 Real part impedance spectrum of a bonded PWAS: a) impedance at the elevated temperature, and b) amplitude of impedance peak at the elevated temperature.

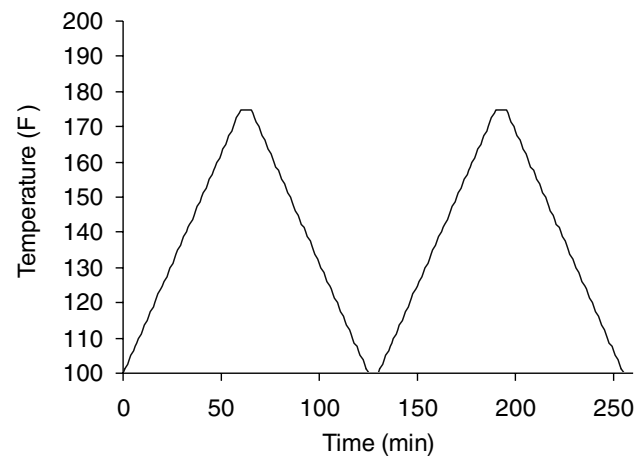

Fig. 7 Temperature cycling graph.

submerged into the liquid nitrogen and kept for 10 min before measurements to test the survivability. The impedance signatures were measured by a Hewlett Packard 4194A Impedance analyzer. The real part of impedance signature indicated that free PWAS, when subjected to liquid nitrogen at cryogenic temperatures, maintained their EM impedance (Fig. 2). The first resonance frequency increased from 344 to $362 \mathrm{kHz}$. Initial impedance signature of free PWAS was recovered when PWAS was warmed to room temperature.

The short-term operation temperature of M-bond 200 is from -300 to $+200^{\circ} \mathrm{F}$. Bonded PWAS with M-Bond 200 adhesive did not survive the cryogenic cycling. However, AE-15 maintained its ability during cryogenic cycling. Figure 3 shows the real part of impedance signatures taken from a bonded PWAS specimen with AE-15 adhesive that was submerged into liquid nitrogen for 10 times. The specimen was submerged in the liquid nitrogen for $10 \mathrm{~min}$ before each impedance measurement. Figure $\underline{4}$ shows the real part of impedance signatures taken from the bonded PWAS specimen at room temperature after each submersion. The real part of the impedance retained its peaks and their relative frequency location. No major EM impedance changes were recorded for both free and bonded PWAS working at cryogenic temperature. The reverberated response is significantly higher under submersion than in air (e.g., approximately $1800 \Omega$ at $5 \mathrm{kHz}$ under submersion vs $400 \Omega$ at $5 \mathrm{kHz}$ in air), which indicates more damping when submerged, as expected. However, the damping of the resonance peaks is more elaborate to deduce and would need a separate study.

\section{B. High Temperature}

Three requirements that must be considered for high temperature piezoelectric applications would be the Curie transition temperature, the pyroelectric properties, and the ferroelectric properties [19,20]. The Curie transition temperature must be well above the operating temperature, or depolarization may occur under combined temperature and pressure conditions. The thermal energy facilitates displacement of domain walls, leading to the large power dissipation and hysteretic behavior especially closed to the Curie transition temperature. The temperature variation may produce pyroelectric charges, which may interfere with the piezoelectric effect. In addition, many ferroelectrics become conducting at high temperatures, leading to the charge drifts and partial loss of signal. The conductivity problem is aggravated during operation in atmosphere with low oxygen content, in which many oxygen-containing ferroelectrics may rapidly lose oxygen and become semiconducting.

A free PWAS was subjected to a series of high temperatures in an oven for $30 \mathrm{~min}$ time intervals. After each $30 \mathrm{~min}$, the PWAS was cooled and their impedance spectrums were measured in room
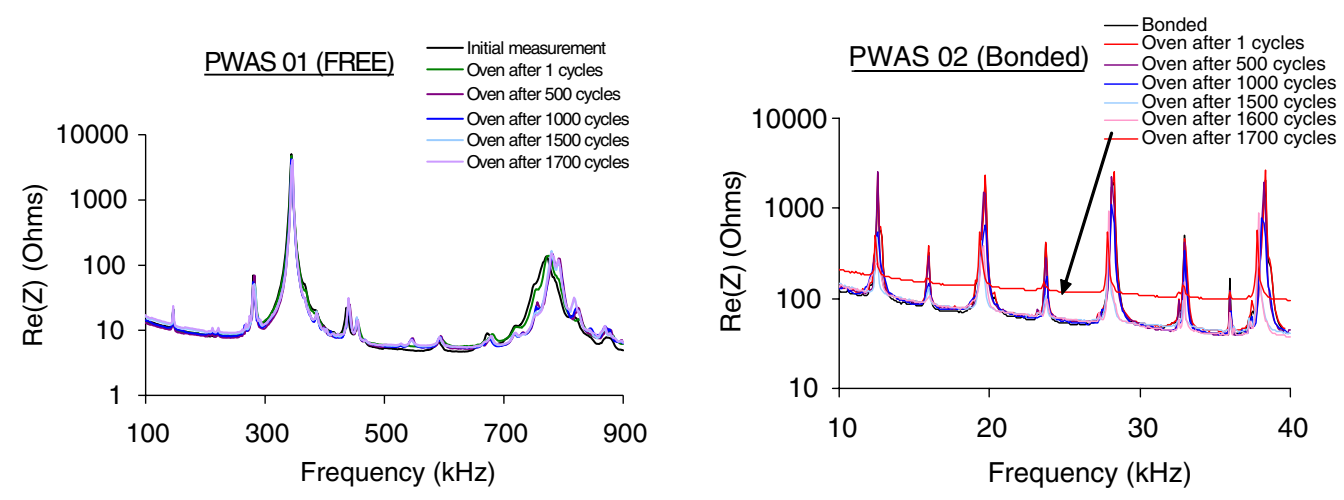

a)

b)

Fig. 8 EM impedance spectrum of PWAS after exposure to temperature cycling: a) free PWAS, and b) attached PWAS on a metallic plate. 


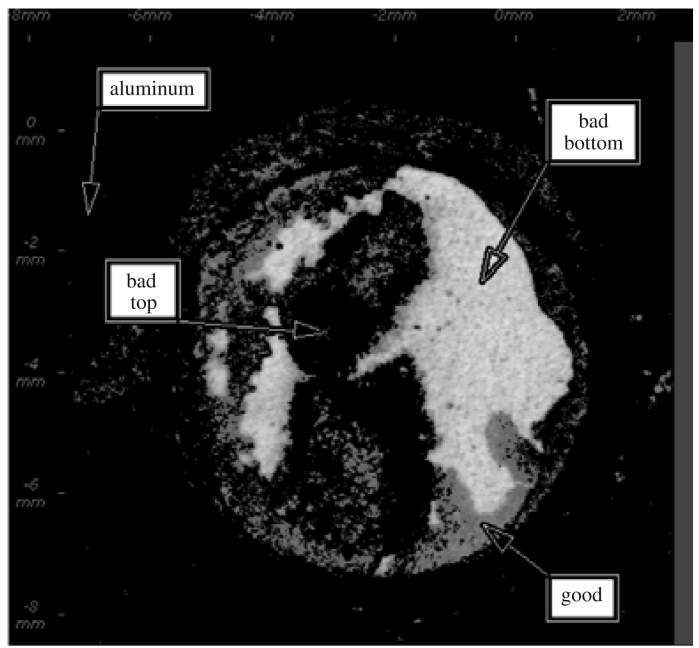

a)

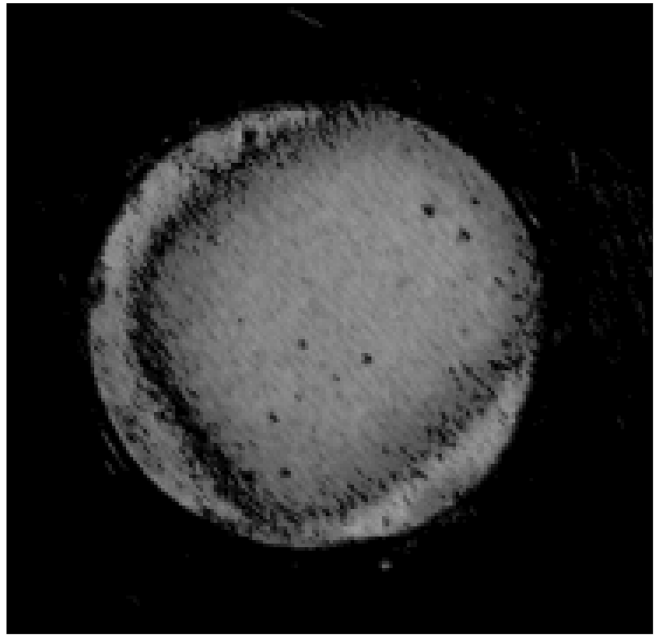

b)

Fig. 9 C-Scan adhesive and PWAS interface images of a) bad bond specimen, and b) good bond specimen.

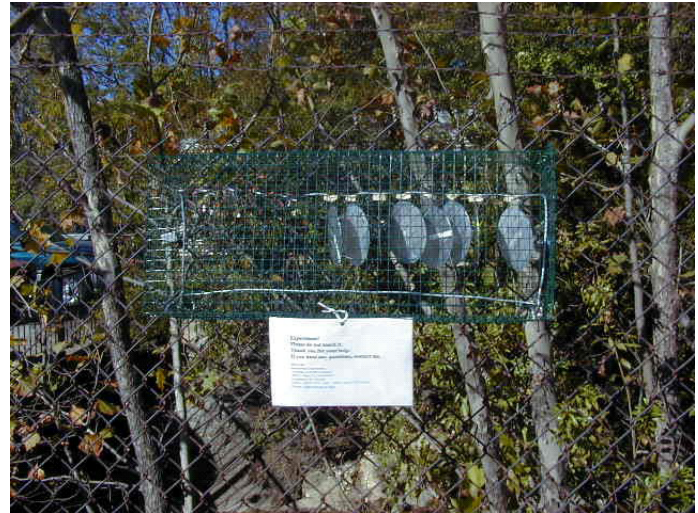

a)
Average Temperature in Columbia, SC

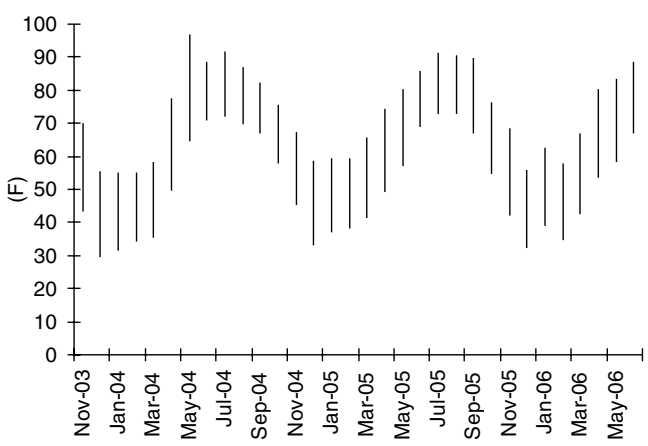

b)

Fig. 10 a) Environmental testing of free and attached PWAS: a) outdoors test fixture, and b) temperature profile.

temperature. Figure 5 a shows the real part impedance spectrum of a free PWAS measured in room temperature and the real part impedance spectrums of the PWAS after exposure to oven temperatures ranging from 100 to $700^{\circ} \mathrm{F}$ with $100^{\circ} \mathrm{F}$ increment. The Curie temperature for PZT PWAS is $625^{\circ} \mathrm{F}$. As seen in the Fig. $\underline{\text { 5a, }}$, under $500^{\circ} \mathrm{F}$, the real part impedance spectrums of PWAS possesses two strong antiresonant peaks due to the intrinsic electromechanical impedance of the free PWAS. With the further increment of oven temperature PWAS lost its piezoelectric effect, which is manifested by the loss of antiresonance peaks in real part impedance spectra. Figure $5 \mathrm{~b}$ shows the free PWAS was able to maintain its antiresonance peak amplitude at the room temperature after the shortterm heating up to $500^{\circ} \mathrm{F}$. This suggested that free PWAS can survive after heating up to $500^{\circ} \mathrm{F}$.

A bonded PWAS was subjected to high temperature in the oven with the similar setup as the free PWAS. Because of the high temperatures, extra care must be taken for the bonding of sensors. Vishay adhesive M-Bond 610 has a short-term operating temperature range from -452 to $+700^{\circ} \mathrm{F}$ and a long-term operating temperature range from -452 to $+500^{\circ} \mathrm{F}$. The PWAS durability test for bonded PWAS at high temperature used M-Bond 610 adhesive. PWAS impedance spectrums were measured at the oven. Figure 6 a shows the real part impedance spectrum of the bonded PWAS after exposure to oven temperatures ranging from 100 to $600^{\circ} \mathrm{F}$ with $100^{\circ} \mathrm{F}$ increment. As seen in the figure, the real part impedance spectrums of bonded PWAS antiresonant frequencies and amplitudes reduced after increasing the temperature. At temperature above $400^{\circ} \mathrm{F}$, the real part of impedance spectrum becomes very small. After reaching the Curie temperature, the bonded PWAS lost its piezoelectric effect. Figure $6 \mathrm{~b}$ shows the first antiresonance peak amplitude remain the same when the environmental temperature was below $200^{\circ} \mathrm{F}$. The amplitude started to drop above $200^{\circ} \mathrm{F}$. However, this drop is not as abrupt as noticed for free PWAS above $500^{\circ} \mathrm{F}$. This suggests that the performance of PWAS bonded to aluminum plate with M-Bond 610

Table 3 Piezoelectric wafer active sensor specimen summary (experiment started in November 2003)

\begin{tabular}{lcccc}
\hline $\begin{array}{c}\text { Specimen } \\
\#\end{array}$ & Adhesive & Coating & $\begin{array}{c}\text { Lifetime } \\
\text { (week) }\end{array}$ & $\begin{array}{c}\text { Possible } \\
\text { reason }\end{array}$ \\
\hline Bond1 & AE-10 & None & 117 & Adhesive \\
Bond2 & AE-10 & Acrylic & 120 & good \\
Bond3 & AE-10 & Silicon & 117 & Adhesive \\
Bond4 & AE-10 & Polyurethane & 84 & Adhesive \\
Bond5 & M-Bond 200 & Acrylic & 107 & Adhesive \\
Bond6 & M-Bond 200 & Silicon & 138 & Adhesive \\
Bond7 & M-Bond 200 & Polyurethane & 91 & adhesive \\
Bond8 & M-Bond 200 & None & 107 & PWAS cracked \\
Free1 & - & None & 91 & Lost \\
Free2 & - & Polyurethane & 120 & Good \\
Free3 & - & Silicon & 120 & Good \\
Free4 & - & None & 91 & Electrode defects \\
Free5 & - & Polyurethane & 120 & Good \\
Free6 & - & Acrylic & 84 & Lost \\
Free7 & - & Silicon & 120 & Good \\
Free8 & - & Acrylic & 84 & Lost \\
\hline \hline
\end{tabular}




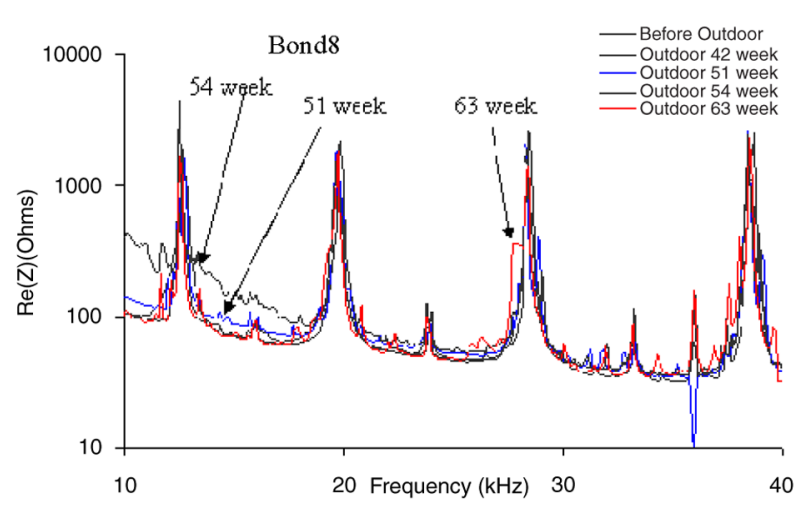

a)

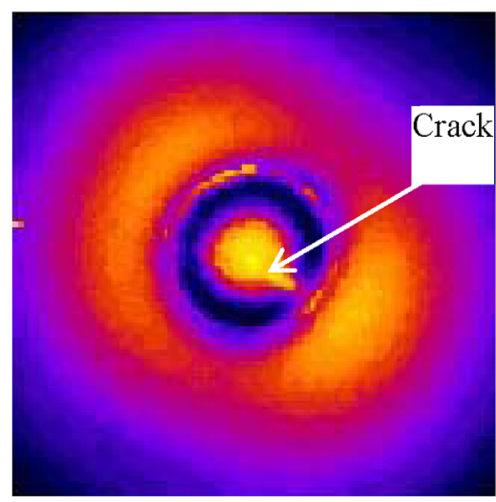

b)

Fig. 11 a) EM impedance spectrum of specimen Bond8, and b) asymmetric displacement field [묘] .

adhesive is constant up to $200^{\circ} \mathrm{F}$ and starts to degrade thereof. The earlier onset of degradation for bonded PWAS in comparison to free PWAS may be attributed to 1) softening of organic adhesive due to temperature and 2) mismatch of thermal expansions between PWAS and structural substrate. Further studies would be necessary to quantify these outputs.

\section{Temperature Cycling}

The first temperature cycling set included one free PWAS-01 and one attached PWAS-02. The Vishay strain gage M-Bond 200 adhesive was used and the strain gage installation procedure was followed to apply the APC-850 PWAS to the aluminum alloy plate.

For temperature cyclic testing, free and attached PWAS were placed in an oven and exposed to a temperature variation between 100 and $175^{\circ} \mathrm{F}$. The temperature cycle consisted of a slow rise from 100 to $175^{\circ} \mathrm{F}$ followed by a 5 -min dwell at $175^{\circ} \mathrm{F}$, then a slow descend from 175 to $100^{\circ} \mathrm{F}$ followed by a 5 -min dwell at $100^{\circ} \mathrm{F}$ (Fig. 7). The peak of test environmental temperature is $25^{\circ} \mathrm{F}$ higher than the adhesive normal operating temperature. The data taken at the beginning of this experiment showed a settling in effect, that is, some amplitude reduction during the first few cycles, followed by a leveling off of the variations. The free PWAS survived the temperature cycling without any significant change in the EM impedance spectrum. In total, 1700 cycles have been performed (11 months of testing). The free PWAS survived 1700 oven cycles without significant changes in the EM impedance spectrum (Fig. 8a). Attached PWAS survived 1400 cycles in the oven without significant changes in the EM impedance spectrum. The spectrum taken after 1500 and 1600 cycles showed small changes. The spectrum taken after 1700 cycles showed marked changes shown in Fig. 8b, which were attributed to the failure of the attached PWAS.

Further investigation with a Quantum 350 scanning acoustic microscope** indicated that disbond between PWAS and substrate took place. Figure 9a showed C-scan adhesive and PWAS interface images of the PWAS -02 specimen after 1700 cycles. We can easily identify some disbond areas. There are four distinct regions on the $\mathrm{C}$-scan interface image, namely the black background (aluminum plate), white interface (probable disbond at the adhesive/PWAS interface), gray interface (good bond), and black interface (probable disbond at the aluminum/adhesive interface). In comparison, we put a $\mathrm{C}$-scan image of good bond specimen in Fig. 9b. Hence, it was concluded that the failure was not due to the piezoelectric material failure, but due to the failure of the bonded interface between the PWAS and the substrate. The operating temperature is beyond the adhesive normal working range; this failure can be attributed to the repeated differential thermal expansion for the adhesive layer between the ceramic PWAS and the metallic substrate.

The second temperature cycling test set also included one free PWAS-03 and one attached PWAS-04. Vishay strain gage M-Bond

\footnotetext{
**This investigation was done in collaboration with Peter Nagy of the University of Cincinnati, which has this facility.
}

$\mathrm{AE}-10$ adhesive was used in this set. The operating temperature range is from cryogenic region to $200 \mathrm{~F}$. M-Bond AE-10 is a $100 \%$-solids epoxy system. For this set of temperature cyclic testing, free and attached PWAS were placed in an oven and exposed to the same temperature cycling previously described. The data taken at the beginning of this experiment showed a similar settling in effect. The free PWAS and attached PWAS survived the temperature cycling without any significant change in the EM impedance spectrum after 1000 cycles.

\section{Environmental Outdoor Exposure}

Free PWAS and attached PWAS were exposed to the outdoors environment (Fig. 10a) over a long time period. In this study, several adhesives and several protective coatings were examined (Table $\underline{3}$ ). The measured quantity was the EM impedance spectrum. The data taken at the beginning of these experiments showed a settling in effect, that is, some amplitude reduction during the first few cycles, followed by a leveling off of the variations. After this, the EM impedance data stayed rather constant for the duration of the test. This test has been conducted for 120 weeks and average temperature was shown in Fig. 10b. Minor repairs to the wire attachments were done. So far, significant changes of PWAS EM impedance spectrum have been noticed in the attached PWAS specimen. Free PWAS are still in good working condition. A brief description of all the PWAS conditions can be found in Table 3 .

For sample Bond8, this sample used the cyanoacrylate fast adhesive and had no protective coating. The historical evolution of the EM impedance spectrum for this sample is shown in Fig. 11a: up to 42 weeks, no significant changes were recorded; at 51 weeks, small changes were observed. The main peak dropped a little and more small peaks can noticed. At 54 weeks, more changes were observed. At 63 weeks, significant changes were observed. The main peak dropped a lot and more small peaks appeared. At this stage, the sample was sent to Dr. Blackshire at Air Force Research Laboratory, where it was subjected to laser scanning interferometer investigation [18]. An asymmetry in the displacement field and large amplitude edge vibrations indicative of incipient disbonding were found (Fig. 11b). In addition, a crack was detected in the PWAS under optical microscope investigation [18]. The crack was located

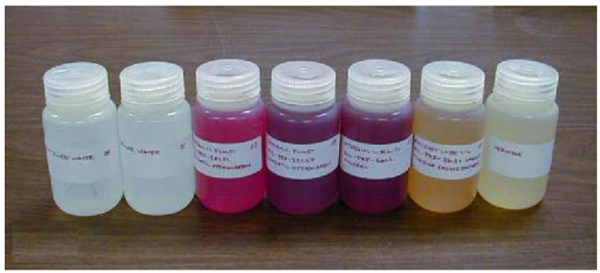

a)

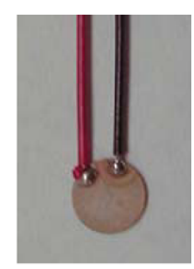

b)
Fig. 12 PWAS submersion test: a) test containers, and b) 5-mm diameter free PWAS specimen. 

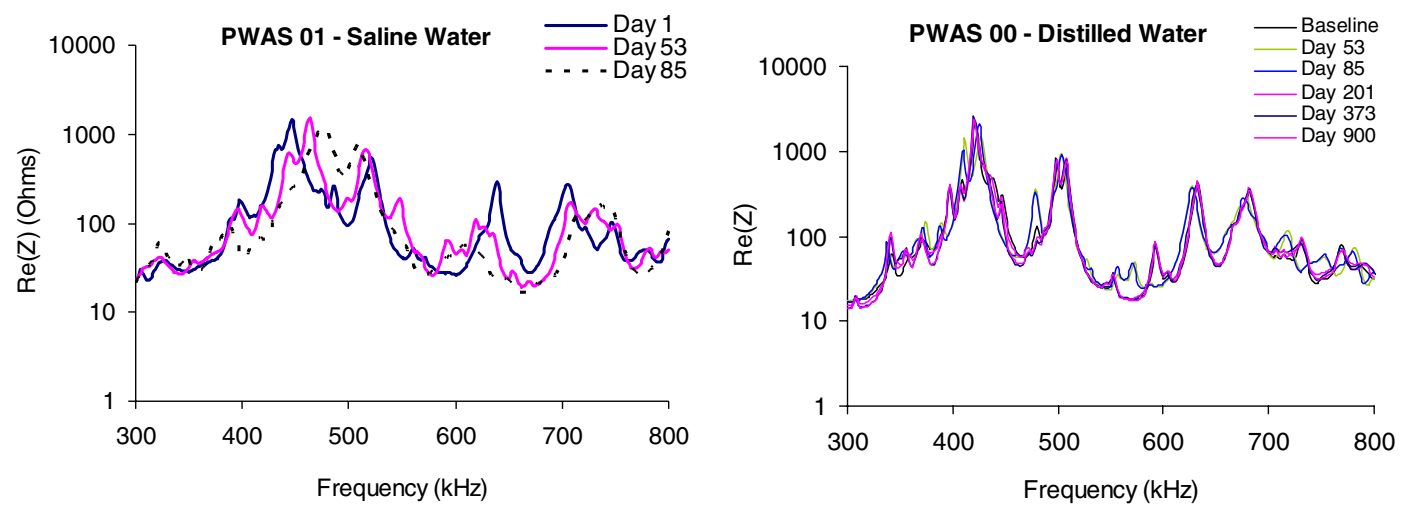

a)

b)

Fig. 13 EM impedance spectrum of PWAS after submersion exposure: a) PWAS in saline water, and b) PWAS in distilled water.

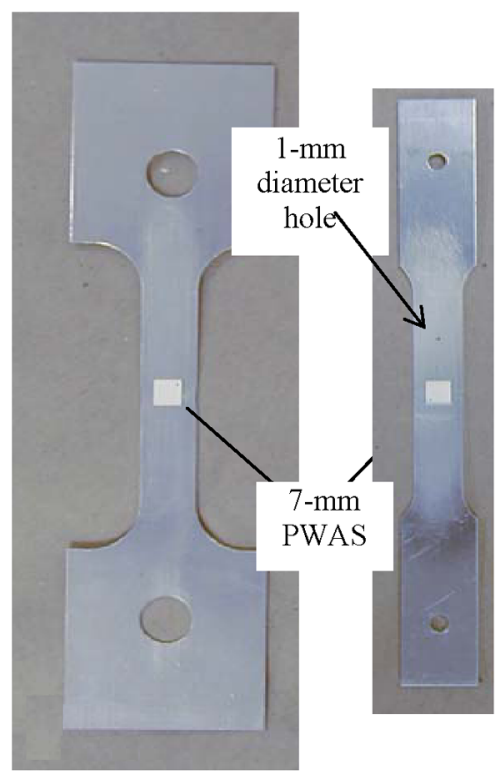

a)

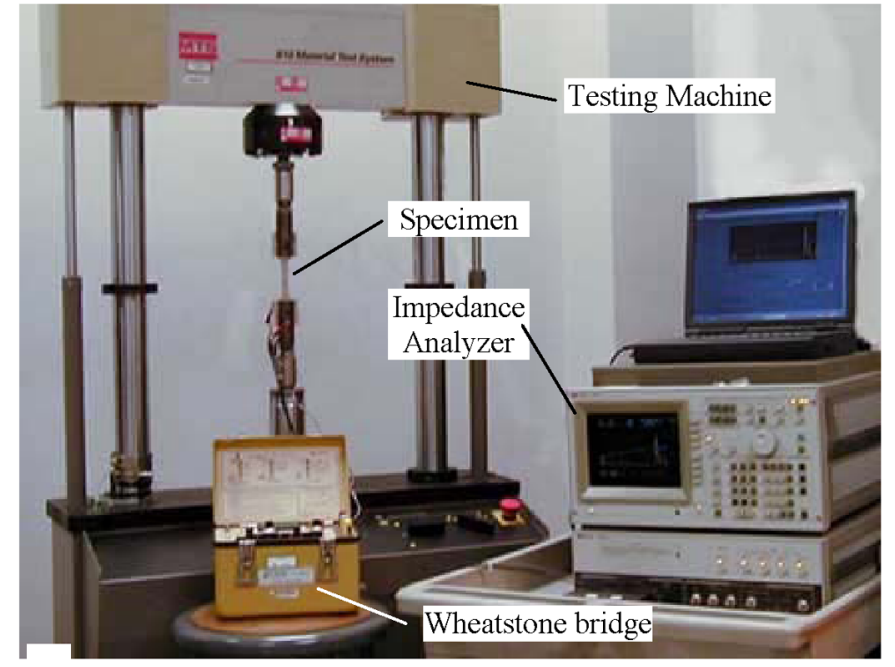

c)

Fig. 14 Large strains and fatigue cyclic loading tests: a) large-strain test specimen, b) fatigue cycling loading test specimen, and c) experimental setup [21].

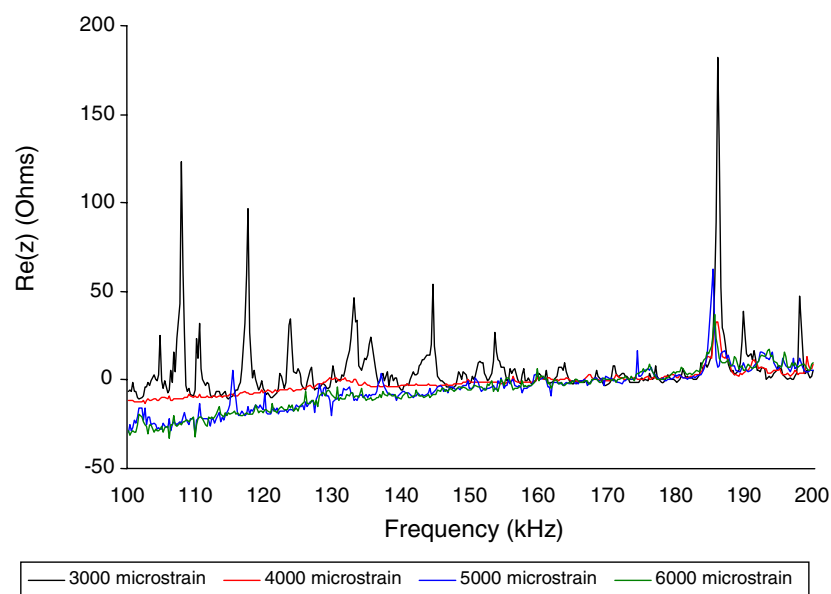

a)

Fig. 15 Large-strain tests: a) impedance signatures up to $6000 \mu \varepsilon$, and b) micrograph of the cracked PWAS at 7200 $\mu \varepsilon[\underline{21}]$.

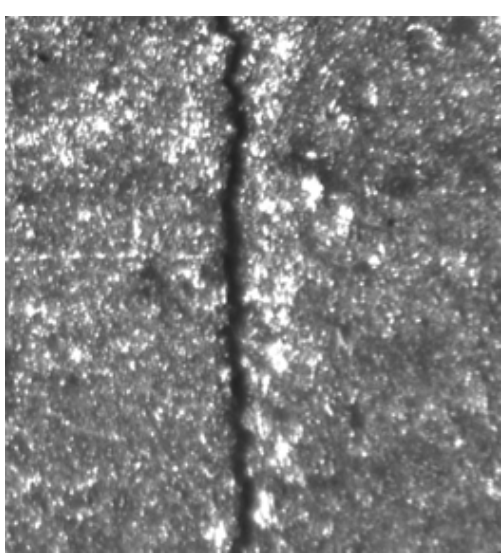

b) 


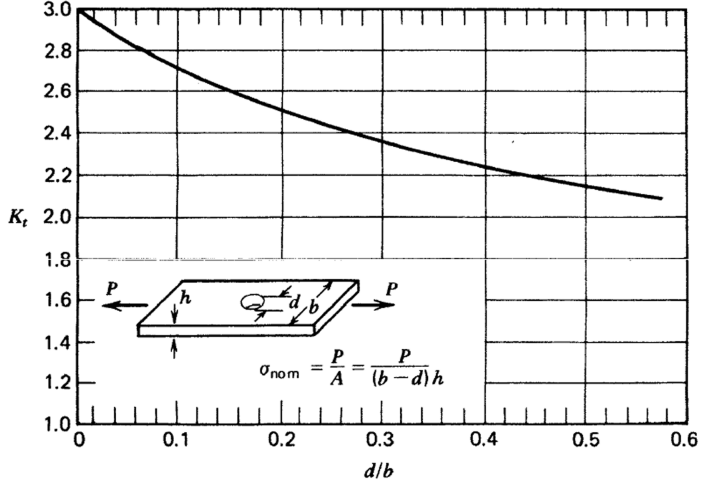

a)

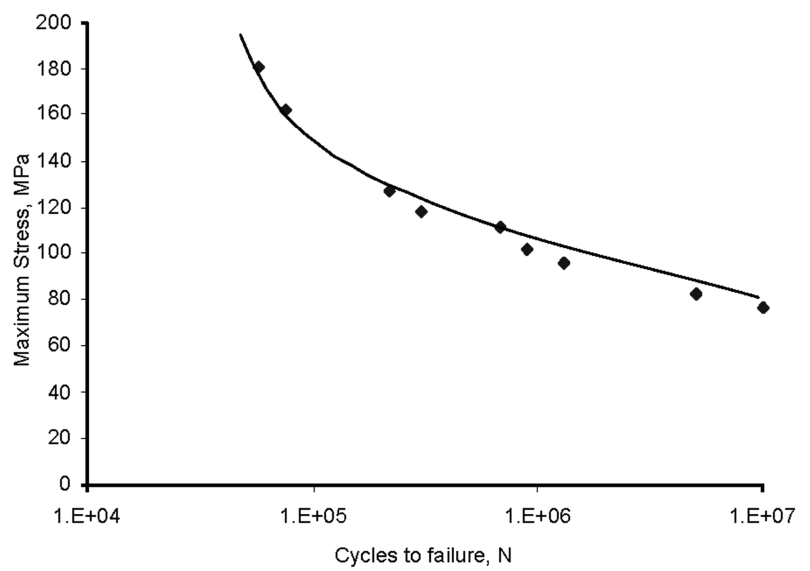

b)

Fig. 16 a) Stress-concentration factor for flat plate with hole, and b) S-N curve determined during reported work [21].

diagonally in the right lower corner. These effects may explain the changes noted in the EM impedance spectrum. The Bond8 was received back and continued its outdoors test. The impedance spectrum was still recoded until final reading at 84 weeks. After that, the specimen completely was inactivated and impedance spectrum did not reflect the structure information anymore.

\section{E. Submersion Exposure}

The purpose of these tests was to determine how PWAS behaves when exposed to water and various maintenance fluids. The specimens used in this experiment were free 5-mm APC-850 PWAS with two connecting wires soldered by the manufacturer. The PWAS were submerged in plastic bottles containing the fluids (Fig. 12). The fluids used in the submersion test were distilled water $(0)$, saline solution (1), hydraulic fluid MIL-PRF- 83282 synthetic hydrocarbon (2), ; hydraulic fluid MIL-PRF- 87257 synthetic hydrocarbon (3), hydraulic fluid MIL-PRF- 5606 mineral (4), aircraft cube oil MILPRF-7808L grade 3 turbine engine synthetic (5), and kerosene (6).

This test has been conducted for over 900 days (128 weeks). So far, no significant changes have been noticed in the PWAS EM impedance spectrum except for the PWAS submerged in saline solution (Fig. 13). The PWAS submerged in saline solution survived only a little over 85 days (15 weeks). The EM impedance reading taken at 85 days exposure showed marked differences from the previous readings. The failure of this PWAS was traced to the detachment of the soldered connection. This can be attributed to the corrosive effect of the saline solution.

\section{F. Large Strains and Fatigue Cyclic Loading}

Doane and Giurgiutiu [21] studied the behavior of PWAS transducers under large strains and under fatigue cyclic loading. To test the characteristics of the PWAS under large-strain conditions, a PWAS was bonded to aircraft grade 2024-T3 aluminum alloy test specimen and subjected to tensile loading.

In the large-strain experiments, the specimen shown in Fig. 14a was used [21]. The specimens were fabricated from $2024 \overline{\mathrm{T} 3}$ aluminum with a nominal thickness of $1 \mathrm{~mm}$. The specimens were loaded in tension under strain control. Two specimens were used: the

Table 4 Fatigue specimens overview $(R=0.1)[21]$

\begin{tabular}{lrrrrr}
\hline \hline & PWAS & PWAS & PWAS & PWAS & PWAS \\
& \multicolumn{1}{c}{ P1 } & F2 & F3 & F4 & F5 \\
\hline Maximum load & $2104 \mathrm{~N}$ & $1560 \mathrm{~N}$ & $1335 \mathrm{~N}$ & $1156 \mathrm{~N}$ & $1067 \mathrm{~N}$ \\
Minimum load & $210 \mathrm{~N}$ & $156 \mathrm{~N}$ & $134 \mathrm{~N}$ & $116 \mathrm{~N}$ & $107 \mathrm{~N}$ \\
Mean load & $1157 \mathrm{~N}$ & $858 \mathrm{~N}$ & $734 \mathrm{~N}$ & $636 \mathrm{~N}$ & $587 \mathrm{~N}$ \\
$\begin{array}{l}\text { Cycles to specimen } \\
\text { failure }\end{array}$ & $178 \mathrm{kc}$ & $670 \mathrm{kc}$ & $1.3 \mathrm{Mc}$ & $6.25 \mathrm{Mc}$ & $12.2 \mathrm{Mc}$ \\
\hline \hline
\end{tabular}

first one was loaded up to 5000 microstrain, the other up to failure. Measurements were taken at 200 microstrain intervals. The baseline impedance was recorded at zero strain and additional readings were recorded until failure of the PWAS occurred. Minimal changes occurred to the impedance signature until the value of 3000 microstrain was exceeded. Significant changes begin to happen after 3000 microstrain. After 6000 microstrain, the changes in the EM impedance were very strong (Fig. 15a). Eventually the PWAS failed in tension at approximately $720 \overline{0}$ microstrain [21]. The PWAS failure was in the form of a transverse crack (Fig. $1 \overline{5 b}$ ).

In the fatigue cyclic loading experiments, the specimen shown in Fig. 14b was used [21]. The specimens were fabricated from 2024 T3 aluminum with a nominal thickness of $1 \mathrm{~mm}$. A 7-mm square PWAS was bonded to the specimen with M-Bond 200 cyanoacrylate adhesive. A 1-mm hole was drilled into the specimen to act as stress concentration and localize the fatigue failure. Five specimens were used (Table 4). The specimens were loaded in fatigue cyclic loading with the mean loads and amplitudes adjusted such as to cause failure of the aluminum substrate at various values between 100 thousand and 10 million cycles (Fig. 16 and Table 4). The baseline impedance reading was taken with the mean load applied at the beginning of the tests and at predetermined cyclic intervals. Small settle-in changes occurred in the impedance readings in the first 30-40 thousand cycles. Beyond this the PWAS readings were relatively unchanged until the metallic specimen finally broke under fatigue cyclic loading. The specimen failure always occurred at the 1-mm stressconcentration hole. The PWAS survived the fatigue failure of all the metallic specimens.

\section{Conclusions}

This research considered the durability and survivability of the PWAS transducers under various exposures (cryogenic and high temperature, temperature cycling, freeze-thaw, outdoor environment, operational fluids, large strains, and fatigue load cycling). In most cases, the PWAS survived the tests successfully. The cases when the PWAS did not survive the tests were closely examined and possible cause of failure was discussed. The test results indicated that PZT PWAS can be successfully used in a cryogenic environment; however, it does not seem to be a good candidate for high temperature. Repeated differential thermal expansion and extended environmental attacks can lead to PWAS failure. This emphasizes the importance of achieving the proper design of the adhesive bond between the PWAS and the structure, and of using protective coating to minimize the ingression of adverse agents. The high-strain tests indicated that the PWAS remained operational up to at least 3000 microstrain and failed beyond 6000 microstrain. The fatigue cyclic loading, conducted up to 12 millions of cycles, showed that the PWAS transducers sustained at least as many fatigue cycles as the structural coupon specimens on which they were installed. These 
results gave us confidence in this new technology and opened the path toward installation on realistic aerospace specimens. For longerterm durability and survivability results, further tests are being planned for subsequent studies. The modeling of the temperature effect could be done by combining the complete analytical model of free and bonded PWAS on circular plates as a function of material properties of PWAS and structures and the dielectric and piezoelectric properties of PZT ceramics for capacitor and actuator applications at cryogenic temperatures [22].

\section{Acknowledgments}

The financial support of National Science Foundation award \# CMS 0408578 and CMS 0528873, program director Shih Chi Liu, and Air Force Office of Scientific Research grant \# FA9550-04-0085 are gratefully acknowledged. Any opinions, findings, and conclusions or recommendations expressed in this material are those of the authors and do not necessarily reflect the views of the National Science Foundation and Air Force Office of Scientific Research. Collaboration of James L. Blackshire from Air Force Research Laboratory and help from Peter Nagy at the University of Cincinnati are acknowledged.

\section{References}

[1] Chang, F.-K., "Built-In Damage Diagnostics for Composite Structures," Proceedings of the 10th International Conference on Composite Structures (ICCM-10), Vol. 5, Woodhead Publishing, Cambridge, England, Aug. 1995, pp. 283-289.

[2] Chang, F.-K., "Manufacturing and Design of Built-in Diagnostics for Composite Structures," 52nd Meeting of the Society for Machinery Failure Prevention Technology, Vibration Institute, Haymarket, VA, April 1998.

[3] Wang, C. S., and Chang, F.-K., "Built-In Diagnostics for Impact Damage Identification of Composite Structures," Structural Health Monitoring 2000, edited by Fu-Kuo Chang, Technomic, Lancaster, PA, 2000, pp. 612-621.

[4] Lin, X., and Yuan, F. G., "Diagnostic Lamb Waves in an Integrated Piezoelectric Sensor/Actuator Plate: Analytical and Experimental Studies," Smart Materials and Structures, Vol. 10, No. 5, 2001, pp. 907-913. doi:10.1088/0964-1726/10/5/307

[5] Lin, X., and Yuan, F. G., "Damage Detection of a Plate using Migration Technique," Journal of Intelligent Material Systems and Structures, Vol. 12, No. 7, July 2001, pp. 469-482.

[6] Ihn, J.-B., and Chang, F.-K., "Built-In Diagnostics for Monitoring Crack Growth in Aircraft Structures," 9th International Symposium on Smart Structures and Materials, SPIE, Bellingham, WA, 2002.

[7] Giurgiutiu, V., "Structural Health Monitoring with Piezoelectric Wafer Active Sensors," Academic Press, New York, 2008, p. 747, ISBN 9780120887606

[8] Crawley, E. F., and de Luis, J., "Use of Piezoelectric Actuators as Elements of Intelligent Structures," AIAA Journal, Vol. 25, No. 10, 1987, pp. 1373-1385. doi: $10.2514 / 3.9792$

[9] Sirohi, J., and Chopra, I., "Fundamental Understanding of Piezoelectric Strain Sensors," Journal of Intelligent Material Systems and Structures, Vol. 11, No. 4, 2000, pp. 246-257.
[10] Park, G., "Overview of Piezoelectric Impedance-Based Health Monitoring and Path Forward," The Shock and Vibration Digest, Vol. 35, No. 6, Nov. 2003, pp. 451-463. doi: $10.1177 / 05831024030356001$

[11] Xu, Y. G., and Liu, G. R., "A Modified Electro-Mechanical Impedance Model of Piezoelectric Actuator-Sensors for Debonding Detection of Composite Patches," Journal of Intelligent Material Systems and Structures, Vol. 13, No. 6, 2002, pp. 389-396. doi: $10.1177 / 104538902761696733$

[12] Park, G., Farrar, C. R., Di Scalea, F., and Coccia, S., "Performance Assessment and Validation of Piezoelectric Active-Sensors in Structural Health Monitoring," Smart Materials and Structures, Vol. 15, No. 6, 2006, pp. 1673-1683. doi:10.1088/0964-1726/15/6/020

[13] Isogai, Y., Miyayama, M., and Yanagida, H., "Piezoelectric Actuator Responsive to Environmental Humidity," Journal of the Ceramic Society of Japan, Vol. 102, No. 6, 1994, pp. 536-539.

[14] Wang, Y., Chu, W. Y., Su, Y. J., and Qiao, L. J., "Stress Corrosion Cracking of PZT Piezoelectric Ceramics," Materials Letters, Vol. 57, Nos. 5-6, Jan. 2003, pp. 1156-1159. doi:10.1016/S0167-577X(02)00948-5

[15] Qing, X. P., Beard, S. J., Kumar, A., Sullivan, K., Aguilar, R., Merchant, M., and Taniguchi, M., "The Performance of a Piezoelectric-SensorBased SHM System Under a Combined Cryogenic Temperature and Vibration Environment," Smart Materials and Structures, Vol. 17, No. 5, Oct. 2008, pp. 1-11.

[16] Qing, X. P., Chan, H.-L., Beard, S. J., Ooi, T. K., and Marotta, S. A., "Effect of Adhesive on the Performance of Piezoelectric Elements Used to Monitor Structural Health," International Journal of Adhesion and Adhesives, Vol. 26, No. 8, 2006, pp. 622-628. doi:10.1016/j.ijadhadh.2005.10.002

[17] Sakai, T., Terai, Y., and Ishikiriyama, M., "Improvement in Durability of Piezoelectric Ceramics for Actuator," Japanese Journal of Applied Physics, Vol. 34, No. 9B, 1995, pp. 5276-5278. doi:10.1143/JJAP.34.5276

[18] Blackshire, J. L., Giurgiutiu, V., Cooney, A., and Doane, J., "Characterization of Sensor Performance and Durability for Structural Health Monitoring," Advanced Sensor Technologies for Nondestructive Evaluation and Structural Health Monitoring, SPIE, Bellingham, WA, 2005.

[19] Kirk, K. J., McNab, A., and Hayward, G., "Monolithic Arrays for Monitoring Industrial Plant at High Temperatures," Proceedings of Ultrasonics Symposium, Vol. 2, Nov. 1994, pp. 1125-1128.

[20] Krispel, F., Reiter, C., Neubig, J., Lenzenhuber, F., Krempl, P. W., Wallnofer, W., and Worsch, P. M., "Properties and Applications of Singly Rotated GaPO4 Resonators," Frequency Control Symposium and PDA Exhibition, May 2003, pp. 668-673.

[21] Doane, J., and Giurgiutiu, V., "An Initial Investigation of the Large Strain and Fatigue Loading Behavior of Piezoelectric Wafer Active Sensors," Health Monitoring and Diagnostics, Sensors and Smart Structures Technologies for Civil, Mechanical, and Aerospace Systems, IEEE Publications, Piscataway, NJ, 2005.

[22] Paik, D.-S., Park, S.-E., Shrout, T. R., and Hackenberger, W., "Dielectric and Piezoelectric Properties of Perovskite Materials at Cryogenic Temperatures," Journal of Material Science and Technology, Vol. 34, No. 3, 1999, pp. 469-473. doi:10.1023/A:1004578225228

N. Wereley Associate Editor 